\title{
Organic solar cells and fully printed super-capacitors optimized for indoor light energy harvesting
}

Balthazar P. Lechêne, Martin Cowell, Adrien Pierre, James W. Evans, Paul K. Wright, Ana C. Arias

Dr. B.P. Lechêne, A. Pierre, Prof. A.C. Arias

Electrical Engineering and Computer Science, University of California Berkeley, CA 94720, USA

E-mail address: acarias@berkeley.edu ; b.lechene@berkeley.edu

\section{Cowell, Prof. P.K. Wright}

Mechanical Engineering, University of California Berkeley, CA 94720, USA

Prof. J. W. Evans

Materials Science and Engineering, University of California, Berkeley, CA 94720, USA

Keywords: Organic Photovoltaics; Indoor; photo-rechargeable system; printed; supercapacitor

\begin{abstract}
:
Flexibility, lightness and printability make organic solar cells (OSC) strong candidates to power low consumption devices such as envisioned for the Internet of Things. Such devices may be placed indoors, where light levels are well below typical outdoors level. Here, we demonstrate that maximizing the efficiency of OSC for indoor operation requires specific device optimization. In particular, minimizing the dark current of the solar cells is critical to enhance their efficiency under indoor light. Cells optimized for sunlight reach $6.2 \%$ power conversion efficiency (PCE). However when measured under simulated indoor light conditions, the PCE is to $5.2 \%$. Cells optimized for indoor operation yield $7.6 \%$ of PCE under indoor conditions. As a proof-of-concept, the solar cells are combined with fully printed super-capacitors to form a photo-rechargeable system. Such a system with a $0.475 \mathrm{~cm}^{2}$ indoor-optimized solar cell achieved a total energy conversion and storage efficiency (ECSE) of $1.57 \%$ under 1 -sun, providing $26 \mathrm{~mJ}$ of energy and $4.1 \mathrm{~mW}$ of maximum power. Under
\end{abstract}


simulated indoor light the system yielded an ECSE of $2.9 \%$, while delivering $13.3 \mathrm{~mJ}$ and 2.8 $\mathrm{mW}$. Those energy and power levels would be sufficient to power low-consumption electronic devices with low duty cycles.

\section{Introduction}

Organic solar cells (OSC) currently achieve more than $10 \%$ of power conversion efficiency (PCE) under 1-sun conditions [1,2] and can be stable over several years $[3,4]$. The materials involved in their fabrication require low processing temperatures, compatible with many plastic substrates $[5,6]$. They can also be completely printed $[7,8]$, allowing the use of large-area, high-throughput, low-cost manufacturing processes such as roll-to-roll printing. As a result, full-scale outdoors demonstrations have already been successfully performed $[9,10]$.

The combination of flexibility, low-cost and short energy payback time makes OSC particularly interesting as an energy harvester for autonomous low-power devices, such as wearables or wireless sensor nodes (WSN) for the Internet of Things. In these new applications, lightness and flexibility become highly desirable and milder operating conditions alleviate materials stability concerns. Typically, WSN are designed as very low-power systems able to gather data from their environment, connect to a network and perform minimal computation tasks, and are self-powered [11,12]. In order to minimize energy consumption WSN operate in cycles, alternating long periods of sleep with very short active periods (of the order of hundreds of milliseconds) during which they perform their tasks. Typically, 10-100 $\mathrm{mW}$ are needed under active mode, while this range falls to 1 to $100 \mu \mathrm{W}$ during the sleeping mode [13-15].

WSN are expected to operate in a wide variety of environments, including indoors, where the available light differs significantly from the conventional 1-sun illumination for which solar cells are usually designed. In contrast to outdoors, there are no clearly defined 
standards to test solar cells in low or indoor lighting conditions, which are typically more varied both in terms of spectrum and intensity. Outdoors, the spectrum is always that of the sun and the intensity usually ranges between $100 \mathrm{~mW} \cdot \mathrm{cm}^{-2}$ and $1 \mathrm{~mW} \cdot \mathrm{cm}^{-2}$. For indoors, it has been reported that, near windows, the light is dominated by the daylight sun spectrum [16]. In places with no access to sunlight, the spectrum of indoor light depends largely on the type of light source used. Earlier work by Minnaert et al.[17] suggests that artificial indoor lighting can be sorted into three categories of spectra, corresponding to incandescent light bulbs, sunlight-type light bulbs such as high temperature compact fluorescent lights (CFL) and all other light sources such as LEDs. Indoor light intensity varies greatly, depending on the type of room, the position, orientation and proximity to the light source. While the intensity right below a lamp or through a window can exceed $1 \mathrm{~mW} \cdot \mathrm{cm}^{-2}$, the intensity in poorly lit rooms can fall under $10 \mu \mathrm{W} \cdot \mathrm{cm}^{-2}$ [18]. Indoor light intensity is usually described by its illuminance, a measure relating the human eye's sensitivity to the light's spectrum. Conversion of illuminance $\left(\varphi\right.$, in lux $\left.=1 \mathrm{~m} \cdot \mathrm{m}^{-3}\right)$ to irradiance $\left(P\right.$, in W. $\left.\mathrm{m}^{-3}\right)$ per unit wavelength $\lambda$ is given by:

$$
\varphi(\lambda)=K_{m} \cdot V_{m}(\lambda) \cdot P(\lambda)
$$

Where $K_{m}$, the maximum photopic luminous efficacy, equals $683 \mathrm{~lm} / \mathrm{W}$ and $V_{m}$ is the spectral luminous efficiency function (Figure S1). Thus, the illuminance is very dependent on the light spectrum. Previous studies on solar cells for indoor conditions have used 400-500 lux as a reference illuminance [17,19] or light intensity ranging from $\sim 1 \mathrm{~mW} . \mathrm{cm}^{-2}$ to below 60 $\mu \mathrm{W} \cdot \mathrm{cm}^{-2}[18,20]$. Several countries establish standards regarding the minimum indoor lighting requirements (such as the IESNA illuminance recommendations in the U.S. or the European Norm 12464-1). In Europe and America, the lowest legal illuminance in buildings (transit areas) is 50-100 lux, and the minimum allowed in offices and commercial buildings usually ranges between 200 to 500 lux. From these considerations, three ranges of indoor 
illuminances are defined: poor lighting (from 0 to 200 lux), typical lighting (200 to 500 lux) and excellent lighting (superior to 500 lux). Converted to irradiance with the AM1.5 spectrum, those illuminance categories correspond respectively to $0-180 \mu \mathrm{W} . \mathrm{cm}^{-2} ; 180-450$ $\mu \mathrm{W} . \mathrm{cm}^{-2}$ and $>450 \mu \mathrm{W} . \mathrm{cm}^{-2}$. To generate the $100 \mu \mathrm{W}$ needed for the sleep mode operation of a WSN in an environment with $450 \mu \mathrm{W} . \mathrm{cm}^{-2}$ of light power available, $2.2 \mathrm{~cm}^{2}$ of a solar cell with $10 \%$ of PCE would be enough. To power the active mode of WSN (10-100 mW), the area of the solar cell would need to be 0.22 to $2.2 \mathrm{~m}^{2}$. Such a big area is not practical for most indoor applications.

To overcome that limitation, one strategy is to take advantage of the cyclical operation of WSN by storing excess energy produced during their sleep period and using it to power the active mode. Super-capacitors are able charge and discharge very rapidly, can withstand many cycles of operation and do not require charge/discharge management electronics. They can be fully printed and made mechanically flexible, thus presenting the same manufacturing advantages as OSC [21,22]. OSC and super-capacitors can be combined to form a system able to simultaneously generate and store energy, called a photo-rechargeable system [23]. Such combinations have previously been demonstrated as part of a complete electronic system,[24] as two separate devices connected together,[25-27] or as a stack forming a single device.[2834] Single-stacks reduce the footprint and the internal series resistance of the system compared to separated solar cells and super-capacitors externally connected [28]. Most of the earlier reports on photo-rechargeable systems use dye-sensitized solar cells (DSSC),[26,30$32,35]$ while a few groups investigate organic solar cells [27,28]. Moreover, all these reports dealt exclusively with outdoor light conditions, with only one [33] investigating intensities between $10 \%$ and $100 \%$ of 1-sun. A metric to consider for photo-rechargeable systems is the energy conversion and storage efficiency (ECSE) of the system. Measured during a chargedischarge cycle, the ECSE is defined as the ratio between the electrical energy that can be extracted from the super-capacitor and the total light energy received by the solar cell during 
the charging step. To the best of our knowledge, the highest reported ECSE of photorechargeable systems to date is $5.12 \%$ with DSSC and $0.82 \%$ for organic solar cells [23].

In this work, we demonstrate that an OSC integrated with a super-capacitor can provide enough energy to power the active mode of WSN operating under indoor-light. In addition, we show that optimization of OSC for low light intensity is different from the 1-sun case and we establish that the ratio of the 1-sun short-circuit current over the dark current the current flowing through the cells when biased in the dark - is a critical parameter to control. The best solar cells for 1-sun achieve $6.2 \%$ of PCE under $100 \mathrm{~mW} . \mathrm{cm}^{-2}$ and $5.2 \%$ under $310 \mu \mathrm{W} . \mathrm{cm}^{-2}$ (typical indoor light), while the solar cells optimized for low light reach $5.7 \%$ under $100 \mathrm{~mW} . \mathrm{cm}^{-2}$ and $7.6 \%$ under $310 \mu \mathrm{W} . \mathrm{cm}^{-2}$. Fully-printed super-capacitors are developed with a maximum capacitance of $130 \mathrm{mF} . \mathrm{cm}^{-2}$, maximum power of $9.8 \mathrm{~mW} . \mathrm{cm}^{-2}$, and maximum energy of $31 \mu \mathrm{W}-\mathrm{hr} . \mathrm{cm}^{-2}$. A photo-rechargeable system comprising a 0.475 $\mathrm{cm}^{2}$ OSC (optimized for indoor conditions) externally connected with a super-capacitor achieves an ECSE of $1.57 \%$ under 1-sun light, and an ECSE of $2.92 \%$ under simulated indoor light $\left(310 \mu \mathrm{W} \cdot \mathrm{cm}^{-2}\right)$.

\section{Experimental}

\subsection{Solar cell fabrication}

ITO-covered glass (from Thin Film Devices) were sequentially cleaned in acetone, isopropanol and water, then passed under UV-ozone plasma treatment for $30 \mathrm{~min}$. PEDOT:PSS (Heraeus Clevios VPAI 4083, $40 \mathrm{~nm}$ ) was spin-coated and baked at $180^{\circ} \mathrm{C}$ for 10 minutes. After transfer in a glovebox, an active layer of poly[N- 9'-heptadecanyl-2,7carbazole-alt-5,5-(4,7-di-2-thienyl-2', 1',3'-benzothiadiazole (PCDTBT) and and [6,6]phenyl- $\mathrm{C}_{71}$-butyric acid methyl ester $\left(\mathrm{PC}_{71} \mathrm{BM}\right)$ in solution $(1: 3.7$ in ortho-dichlorobenzene with 5\% dimethyl sulfoxide) was spin-coated above $(80 \mathrm{~nm})$. PCDTBT was purchased from 
Saint-Jean Photochimie and PC71BM from Solaris. Finally, PEIE (Sigma Aldrich) diluted to $0.048 \mathrm{wt} \%$ or $0.024 \mathrm{wt} \%$ in ethanol was also spin-coated and the whole device was annealed at $70^{\circ} \mathrm{C}$ for 10 minutes. All PEIE layers were too thin to be accurately measured with conventional profilometry methods, suggesting a thickness value below $5 \mathrm{~nm} .200 \mathrm{~nm}$ of aluminum were thermally evaporated to complete the devices.

\subsection{Supercapacitor fabrication}

The super-capacitor are fully dispenser printed. First the polymer binder is dissolved in NMethyl-2-pyrrolidone (NMP) and the carbon powder mixture is suspended in the resulting gel, producing the electrode ink. Then, a $1 \mathrm{~cm}^{2}$ layer of electrode ink is deposited on a stainless steel foil substrate. This wet ink layer is briefly dried in an oven at $60^{\circ} \mathrm{C}$ for 15 minutes. This does not cure the ink completely, but thickens it in preparation for deposition of the next layer. The gel polymer electrolyte layer is deposited next, with its dimensions extending beyond the region covered by the first electrode layer to ensure adequate electrical isolation between electrodes. Both the electrode and electrolyte inks are deposited wet, but solidify once their common NMP solvent is removed. This two layer stack is therefore partially dried in an oven at $60^{\circ} \mathrm{C}$ for 30 minutes again to thicken the top layer in preparation for the final electrode layer. The final electrode is deposited on top of the GPE layer shadowing the dimensions of the bottom electrode. This stack is dried in the oven at $60^{\circ} \mathrm{C}$ for 15 minutes and finally cured at $20^{\circ} \mathrm{C}$ for 96 hours until all the NMP is fully evaporated. The resulting wafer readily separates from the stainless steel substrate and is soaked in BMIMBF4 until saturated. The supercapacitor electrode surfaces are coated in a thin layer of AB powder to reduce interfacial resistance. Stainless steel foils are applied to the AB coated electrode surfaces to act as current collectors during experiments. All super-capacitors in this work have a $1 \mathrm{~cm}^{2}$ area. 


\subsection{Electrical characterization}

For the solar cells, J-V curves were acquired using a Keithley 2400. Voltage measurements were obtained with a Tektronix TDS 5034 oscilloscope. Current measurements in part 4 were obtained using a Keithley 2400 in current sense-mode while sourcing exactly 0 V.For the supercapacitor, power and energy values were acquired using Neware BTS. Calculation of capacitance, series DC resistance, and Coulombic efficiency was done with data from the Neware BTS. Leakage currents of the super-capacitors were measured with a Keithley 2400 held at constant voltage.

\subsection{Light sources}

For the sun spectrum, a solar simulator from Newport Oriel Sol1A (xenon lamp). The power was calibrated with a Newport System V reference silicon solar cell. Neutral density filters from Newport (FBS family, ND04, ND05, ND10, ND20 and ND30) were used to dim the light coming from the solar simulator. The light bulbs used to represent indoor lighting were: GE Softwhite 2800 K (incandescent), GE Energy Smart Daylight CFL 6500K (CFL) and Feit Electric Dimmable A19 LED $3000 \mathrm{~K}$. The light spectra were measured using a Thorlab CSS200 spectrophotometer. The powers of the lamps were adjusted to represent 300 lux with a Hamamatsu S2387-66R silicon photodiode. The expected current of the photodiode was calculated based on its photoresponsivity, the lamp spectrum and the photopic luminous efficacy function.

\section{Results and discussion}

\subsection{Fabrication, characterization and optimization of organic solar cells}

OSC used in this work are fabricated on glass, with a classic architecture (shown in Figure 1 a) using PEDOT:PSS as the hole transport layer, polyethylenimine ethoxylated (PEIE) as the electron transport layer, and an active layerof PCDTBT:PC ${ }_{71} \mathrm{BM}$. PCDTBT is 
used because of its known operational stability.[3] All the fabrication steps are optimized until the cells achieve PCEs on par with previously published works.[36] Under 1-sun, our cells yield $6.2+/-0.2 \%$ of PCE with open circuit voltage $\mathrm{V}_{\mathrm{oc}}=924+/-3 \mathrm{mV}$, short circuit current density $\mathrm{J}_{\mathrm{sc}}=12.1+/-0.1 \mathrm{~mA} \cdot \mathrm{cm}^{-2}$ and fill factor $\mathrm{FF}=56+/-2 \%$ over an area of $0.475 \mathrm{~cm}^{2}$.

\subsubsection{Simulating indoor light}

Throughout this work, light intensity is varied by inserting neutral density filters of known transmittance between the 1-sun (AM 1.5, $100 \mathrm{~mW} . \mathrm{cm}^{-2}$ ) calibrated solar simulator and the solar cells. A power of $310 \mu \mathrm{W} . \mathrm{cm}^{-2}$ is used to represent indoor light. This power corresponds to 340 lux falling in the middle of the typical indoor illuminance range defined in the introduction. We compare the performance of a solar cell under 340 lux of AM 1.5 simulated light and under 300 lux light (since indoor light intensity is characterized by illuminance and not power) from light bulbs of the three different categories determined by Minnaert et al.: one incandescent light bulb of color temperature $2800 \mathrm{~K}$, one $6500 \mathrm{~K} \mathrm{CFL}$ bulb and one LED with 3000K color temperature. The spectra of those four light sources and the absorption of the PCDTBT: $\mathrm{PC}_{71} \mathrm{BM}$ based cells are shown in Figure $\mathbf{1}$ b. The performance of the solar cell under the different light sources are summarized in Table 1. The efficiency of the solar cell under the CFL and the LED is higher $(11.5 \%$ and $8.7 \%$ respectively) than under dimmed sunlight (4.9\%). In the case of the incandescent light bulb, the efficiency is significantly lower $(0.6 \%)$ since a large part of the emitted light spectrum is out of the absorption range of the polymer blend. However, the absolute power generated by the solar cell under the four light sources are much closer. The lowest power per solar cell area is obtained for the incandescent light bulb $\left(3.8 \mu \mathrm{W} . \mathrm{cm}^{-2}\right)$ while the highest is obtained for the CFL $\left(20 \mu \mathrm{W} . \mathrm{cm}^{-2}\right)$. The incandescent light bulb emits a lot more power $\left(0.63 \mathrm{~mW} . \mathrm{cm}^{-2}\right)$ to provide 300 lux of light, so despite the lower PCE of the solar cell under this source, the overall output power is similar to the others. Under 340 lux sunlight the cell generates 15.2 
$\mu \mathrm{W} . \mathrm{cm}^{-2}$ and has an efficiency of $4.9 \%$, falling between the CFL and incandescent bulb. Based on these results, the 340 lux sunlight is used in the remainder of this work to represent indoor lighting.

\subsubsection{Optimization of solar cells for indoor light}

Previous studies on the operation of organic solar cells under low light intensity suggested that an important parameter to control is the shunt resistance. Proctor and Nguyen [37] report that for a shunt resistance $\left(\mathrm{R}_{\mathrm{sh}}\right)$ lower than $1 \mathrm{M} \Omega . \mathrm{cm}^{2}$ the $\mathrm{J}-\mathrm{V}$ characteristics of solar cells can be significantly affected by parasitic leakage current for lights between 100 $\mathrm{mW} . \mathrm{cm}^{-2}$ and $2 \mathrm{~mW} . \mathrm{cm}^{-2}$. Steim et al. [38] show that a shunt resistance of at least $85 \mathrm{k} \Omega . \mathrm{cm}^{2}$ is needed for operation under 1000 lux of a fluorescent lamp and that, overall, the performance of the solar cells under low light increases with higher shunt resistance. Zhou et al. [39] have also developed a solar cell which performs well under room light and exhibits a $\mathrm{R}_{\mathrm{sh}}=10^{8} \Omega \cdot \mathrm{cm}^{2}$.

Here, the thickness of the PEIE layer is varied in order to control the shunt resistance and optimize the organic solar cells for indoor light. Previous studies [40], [41] have shown that PEIE is an insulator which can modify the series resistance and the work function of the cathode as a function of its thickness. PEIE thickness has also been shown to influence the reverse bias saturation dark current in organic photodiodes.[42] Three sets of cells are made with three different PEIE thickness (thin, medium and thick) and their operation is compared under light intensities ranging from $100 \mathrm{~mW} \cdot \mathrm{cm}^{-2}$ to $10 \mu \mathrm{W} \cdot \mathrm{cm}^{-2}$. A PEIE solution concentrated at $0.048 \mathrm{wt} \%$ in ethanol and spin-coated at $5000 \mathrm{rpm}$ (medium thickness) was found to give optimal conditions under 1-sun light intensity, so the other PEIE thicknesses are chosen below (thin: $0.024 \mathrm{wt} \%$ solution of PEIE at $5000 \mathrm{rpm}$ ) and above (thick: $0.048 \mathrm{wt} \%$ solution at $1250 \mathrm{rpm}$ ) this optimal point. Figure 2 a-d gives the variation of the $\mathrm{V}_{\mathrm{oc}}, \mathrm{J}_{\mathrm{sc}}, \mathrm{FF}$ and PCE of representative cells from each group, while Figure 3 a-c gives their J-V 
characteristics for 1 -sun, simulated indoor light $\left(310 \mu \mathrm{W} . \mathrm{cm}^{-2}\right)$ and in dark conditions. The shunt resistances, as extracted from the dark $\mathrm{J}-\mathrm{V}$ characteristics, are $3.3 \mathrm{k} \Omega . \mathrm{cm}^{2}$ for the thin PEIE cell, $32 \mathrm{k} \Omega . \mathrm{cm}^{2}$ for the medium PEIE, and $500 \mathrm{k} \Omega . \mathrm{cm}^{2}$ for the thick PEIE cell. All cells have PCE falling between $5 \%$ and $6 \%$ under 1-sun (the medium thickness is the optimal one, Figure $3 \mathrm{a}$ ), as they have similar $\mathrm{V}_{\mathrm{oc}}$ and $\mathrm{J}_{\mathrm{sc}}$ (respectively within $10 \mathrm{mV}$ and $0.2 \mathrm{~mA} . \mathrm{cm}^{-2}$ of each other). The only difference comes from their FF which can be linked to variations in the series resistance of the devices: the medium and thick PEIE have similar FF, 55\% and 53\% respectively and the thin PEIE FF equals only $48 \%$. The series resistance value of the thin PEIE cell is close to that of a device with no PEIE (direct contact between the active layer and aluminum). Therefore, it can likely be attributed to a less than optimal charge extraction due to too thin of a layer [41]. On the other hand, the thick PEIE cell has a slightly higher series resistance than the medium PEIE cell, suggesting that the insulating nature of the PEIE starts to be impactful. Under this light intensity, the difference in shunt resistances between the three cells has a negligible impact on the FF and the PCE. Overall, varying the thickness of PEIE has a limited effect over the cell efficiency under 1-sun. But the evolution of their PCE differs considerably when light weakens. Under $1 \mathrm{~mW} . \mathrm{cm}^{-2}$ of light, the thin PEIE shows a PCE of $2.1 \%$, the medium PEIE a PCE of $7.4 \%$ and the thick PEIE a PCE of $8.0 \%$. The medium PEIE cell has an $\mathrm{R}_{\text {sh }}$ lower than both minimal values recommended by Proctor et al. and Steim et al., and shows a high PCE under $1 \mathrm{~mW} . \mathrm{cm}^{-2}$ of sunlight ( 1000 lux). This observation suggests that, because of variations from system to system, the shunt resistance may not be a criteria reliable enough to determine how a device will perform under low light intensity. Under typical indoor light $\left(310 \mu \mathrm{W} . \mathrm{cm}^{-2}\right)$, the PCEs of the thin, medium and thick PEIE solar cells are respectively $0.7 \%, 5.2 \%$ and $7.6 \%$. The discrepancy of operation under indoor light of the three cells is well seen in their $\mathrm{J}-\mathrm{V}$ characteristics (Figure 3b): the thin PEIE J-V characteristic is dominated by leakage current resulting in low efficiency, the medium PEIE cell still has a regular diode characteristic but with significant leakage current, 
while the thick PEIE cell displays a diode curve with a high FF (superior to 60\%). The short circuit current (Figure $2 \mathrm{~b}$ ) of all cells follow a linear decrease as a function of light power with a slope close to 1 . The PCE variations with light power originate from the changes in $\mathrm{V}_{\mathrm{oc}}$ and FF. The $\mathrm{V}_{\mathrm{oc}}$ of all cells measured under 1-sun is $920 \mathrm{mV}$ and first decline linearly with the logarithm of light power, with a slope that corresponds to an ideality factor of 1.1.[43] The $\mathrm{V}_{\text {oc }}$ (Figure 2 a) of the thin PEIE and medium PEIE cells do not follow the linear scenario at light intensities of $1-5 \mathrm{~mW} . \mathrm{cm}^{-2}$ and $0.1-0.5 \mathrm{~mW} . \mathrm{cm}^{-2}$ respectively. Similarly, the FF (Figure $2 \mathrm{c}$ ) of the thin PEIE and medium PEIE cells decline sharply at the same light levels as for the $\mathrm{V}_{\mathrm{oc}}$. For both thin and medium PEIE, the $\mathrm{V}_{\mathrm{oc}}$ and FF decreases occur at the light intensities for which the $\mathrm{J}_{\mathrm{sc}}$ generated by the cells reaches the same order of magnitude as their dark currents (Figure $3 \mathrm{c}$ ): the thin PEIE cell has a dark current of about $3.10^{-4} \mathrm{~A} . \mathrm{cm}^{-2}$ (at $0.5 \mathrm{~V}$ of bias) and the decline onset in $\mathrm{V}_{\mathrm{oc}}$ and FF occurs for a light power $\left(4.2 \mathrm{~mW} . \mathrm{cm}^{-2}\right)$ at which the cell's $\mathrm{J}_{\mathrm{sc}}$ equals $6.10^{-4}$ A. $\mathrm{cm}^{-2}$. Similarly for the medium PEIE cell, the decline occurs at a light power between 1 and $0.4 \mathrm{~mW} \cdot \mathrm{cm}^{-2}$, where the $\mathrm{J}_{\mathrm{sc}}$ is between 15 and $6.10^{-5}$ A.cm ${ }^{-2}$ while the dark current equals $2.10^{-5} \mathrm{~A} \cdot \mathrm{cm}^{-2}$ (at $0.5 \mathrm{~V}$ ). The thick PEIE cell has a dark current of $6.10^{-7}$ A.cm ${ }^{-2}$ and does not show any significant decline in either $V_{o c}$ or FF, even when the light falls as low as $10 \mu \mathrm{W} . \mathrm{cm}^{-2}$, for which the $J_{\text {sc }}$ is $2 \mu \mathrm{A} \cdot \mathrm{cm}^{-2}$. These results demonstrate that solar cells intended for indoor operation need to be specifically optimized for these conditions. These results also suggest that the value of the dark current can be used to determine the minimal light power below which a cell's J-V characteristic will start being significantly affected by the dark current, and therefore below which its efficiency will decrease dramatically. Assuming a 1:1 proportional decrease of the cell's current with light intensity, [44] the ratio between the dark current $\left(\mathrm{J}_{\mathrm{dark}}\right)$ and the $\mathrm{J}_{\mathrm{sc}}$ under 1-sun should roughly equal the ratio between the minimal light power $\left(\mathrm{P}_{\min }\right)$ and $100 \mathrm{~mW} \cdot \mathrm{cm}^{-2}\left(\mathrm{P}_{1 \text {-sun }}\right)$ :

$$
\frac{J_{\text {dark }}}{J_{\text {sc }}} \cong \frac{P_{\min }}{P_{1-\text { sun }}}
$$


The ratio of $\mathrm{J}_{0}$ over $\mathrm{J}_{\mathrm{sc}}$ is a more comprehensive criterion than the shunt resistance to control the performance of the solar cells under low light. For example, a solar cell with a 1-sun $\mathrm{J}_{\mathrm{sc}}$ of $20 \mathrm{~mA} \cdot \mathrm{cm}^{-2}$ needs to have a dark current lower than $20 \mu \mathrm{A} . \mathrm{cm}^{-2}$ to be efficient under 0.1 $\mathrm{mW} . \mathrm{cm}^{-2}$, which corresponds to a minimum $\mathrm{R}_{\mathrm{sh}}$ of $25 \mathrm{k} \Omega \cdot \mathrm{cm}^{-2}$. However, a cell generating only $2 \mathrm{~mA} . \mathrm{cm}^{-2}$ under 1 -sun needs a dark current lower than $2 \mu \mathrm{A} . \mathrm{cm}^{-2}$, or a $\mathrm{R}_{\mathrm{sh}}$ higher than $250 \mathrm{k} \Omega \cdot \mathrm{cm}^{-2}$ to be efficient under $0.1 \mathrm{~mW} \cdot \mathrm{cm}^{-2}$. The leakage / short-circuit current ratio criterion provides a useful tool to evaluate the indoor operation potential of solar cells already published. For example, the record cell of $\mathrm{He}$ and coworkers [1] has a dark current of approximately $10^{-4} \mathrm{~mA} \cdot \mathrm{cm}^{-2}$ and a $\mathrm{J}_{\mathrm{sc}}$ under 1 -sun of $17 \mathrm{~mA} \cdot \mathrm{cm}^{-2}$. Therefore, the cell's performance should be significantly limited by dark current at a light power below 0.1 $\mathrm{mW} \cdot \mathrm{cm}^{-2}$.

Steim and colleagues suggest that solar cells should have a series resistance lower than $50 \Omega . \mathrm{cm}^{2}$ for operation under lights of 1000 lux. Here, a solar cell with thick PEIE and 0.475 $\mathrm{cm}^{2}$ of area is connected in series with external resistances ranging from $10 \Omega$ to $33 \mathrm{k} \Omega$ (respectively $4.7 \Omega . \mathrm{cm}^{2}$ and $15.6 \mathrm{k} \Omega . \mathrm{cm}^{2}$ ) and the $\mathrm{J}-\mathrm{V}$ characteristics for each resistance is recorded under 1-sun and $310 \mu \mathrm{W} . \mathrm{cm}^{-2}$. Figure 4 a shows normalized PCE as a function of added series resistance. Figure $\mathbf{4} \mathbf{b}$ and figure $4 \mathbf{c}$ show the $\mathrm{J}-\mathrm{V}$ characteristics obtained under the 1-sun and simulated indoor lighting. Under 1-sun, the PCE shows a high dependence with series resistance, as it decreases rapidly with the increase of resistance, falling to less than 20 $\%$ of its initial value at $515 \Omega$. Under simulated indoor-light however, the PCE is less dependent on series resistance. For a $1 \mathrm{k} \Omega \operatorname{load}\left(475 \Omega . \mathrm{cm}^{2}\right)$, the PCE is above $95 \%$ of its value with no load, and it remains at $80 \%$ for $4.9 \mathrm{k} \Omega\left(2.3 \mathrm{k} \Omega . \mathrm{cm}^{2}\right)$, and at $65 \%$ for $9.8 \mathrm{k} \Omega$ $\left(4.7 \mathrm{k} \Omega . \mathrm{cm}^{2}\right)$. Thus, under indoor-light, series resistance between $475 \Omega . \mathrm{cm}^{2}$ and $2.3 \mathrm{k} \Omega . \mathrm{cm}^{2}$ do not influence the performance of the OSC. This implies that a different set of criteria can be suitable for transparent electrodes. Under low light, optical transparency is more important 
than low resistivity, thus indium tin oxide (ITO) may not be the best choice anymore, as carbon based materials, for example, can offer better light transmittance.[45,46]

\subsection{Fabrication and characterization of the super-capacitors}

The super-capacitor needs to have certain qualities in order to be relevant for the specific application considered. First, it needs to store enough charges to power the WSN and be able to withstand many charge-discharge cycle. Ideally, it would also have the same advantages as the OSC, mainly printability and potential flexibility, and a comparable area. Here, the super-capacitors are all-printed. They consist of composite carbon electrodes sandwiching a gel polymer electrolyte as depicted in Figure 5 a with a $1 \mathrm{~cm}^{2}$ area. The gel polymer acts as a porous separator between the electrodes and houses the ionic liquid electrolyte butyl-methyl-imidazolium tetrafluoroborate (BMIM BF4) allowing ion migration. The electrodes consist of a three-fold composite of activated carbon (AC) (42.5 wt \%), acetylene black (AB) (2.5 wt\%), and graphite (GR) (5 wt\%) held in a polymer binder of poly(vinylidine fluoride-co-hexafluoropropylene) (PVDF-HFP) (50 wt\%). The constituents of these electrodes are chosen to provide both good electrical conductivity and mechanical strength. The high surface area of $\mathrm{AC}$ acts as the main component to support the electric double layer phenomenon responsible for the high-energy storage in super-capacitors. $\mathrm{AB}$ provides electrical pathways between AC grains and improves electrical conductivity within the electrodes. $\mathrm{AB}$ is present at the critical fraction to engender markedly improved electrical conductivity. Graphite's large repeating structural flakes provide mechanical strength and electrical conductivity within the electrode. Finally, the PVDF-HFP binder fraction lends mechanical flexibility to the super-capacitor, and its fraction must be considered a tradeoff between electrical performance and mechanical flexibility. 
Performance testing of the super-capacitor is carried out before coupling with the solar cell to parameterize the response characteristics of the energy storage medium. Constant current charge and discharge is used while tracking the voltage response to determine the super-capacitor capacitance, series resistance, cycle energy and power. Characterization is done over the voltage range of +1.7 to $+0.01 \mathrm{~V}$. This voltage range provides insight about depths of discharge (DoD) up to $99.4 \%$ and fractions thereof. The super-capacitor was discharged at currents between 0.25 and $10 \mathrm{~mA} . \mathrm{cm}^{-2}$ with higher discharge currents producing higher power, lower energy data points. The performance of the super-capacitors are constant even after a hundred thousand cycles, as previously reported.[47] The super-capacitor's series DC resistance is calculated to be approximately $40 \mathrm{ohms}$ during charge and discharge transitions. The supercapacitor's energy and power relationship can be seen in the Ragone plot Figure 5 b, where discharging at varying powers and DoD influences the total energy that can be extracted. The $99 \%$ DoD curve is seen at about ten times higher energy than the 5\% DoD, peaking at $31 \mu \mathrm{W}-\mathrm{hr}(111.6 \mathrm{~mJ})$. Meanwhile, the $5 \%$ DoD curve exhibits higher power by about an order of magnitude, maximizing at $9.8 \mathrm{~mW}$.

Figure $5 \mathbf{c}$ shows the capacitance and the coulombic efficiency (ratio of the discharged vs charged number of charges) of the super-capacitors as a function of the charge and discharge current densities. The highest discharge capacitance, $130 \mathrm{mF} . \mathrm{cm}^{-2}$, was observed for a charge/discharge rate of $0.25 \mathrm{~mA} . \mathrm{cm}^{-2}$. The capacitance increases when the currents are weaker because ions have more time to find optimal packing along the surface of the porous electrode and move deeper into the surface convolutions, in accordance with the porous electrode theory.[48] While the coulombic efficiency remains above $90 \%$ for much of the current range, it drops sharply for current densities lower than $1 \mathrm{~mA} \cdot \mathrm{cm}^{-2}$, likely because of leakage. Super-capacitors inherently show leakage currents when a voltage exists between the super-capacitor's electrodes. Leakage current increases with increasing voltage - often 
approximated as a resistor in parallel with the super-capacitor electrodes.[49] The leakage characteristics of our printed super-capacitors are measured by holding them at a constant voltage and measuring the corresponding current at steady state. The leakage current as a function of bias voltage can be seen in Figure 5 d. As expected, the leakage current increases almost linearly with voltage, for a high value of almost $0.1 \mathrm{~mA} . \mathrm{cm}^{-2}$ for $1.6 \mathrm{~V}$ of bias, which corresponds to a resistance of $16 \mathrm{k} \Omega . \mathrm{cm}^{2}$.

Overall, these super-capacitors offer a wide range of operation in terms of power and cycle energy, in line with the power and energy needs of the low-power autonomous devices identified in the introduction. Their low leakage current and high capacitance make them suitable for integration with the OSC developed in the previous section.

\subsection{Characterization of the energy harvester system}

To demonstrate the potential for energy harvesting of a photo-rechargeable system combining the OSC and super-capacitors, charge-discharge experiments are performed under 1-sun and indoor light. A solar cell $\left(0.475 \mathrm{~cm}^{2}\right)$ either with medium or thick PEIE, a supercapacitor and a $120 \Omega$ resistance are connected in parallel (Figure S2). Switches allow isolation of each component. The current flowing through the super-capacitor and the voltage across it are recorded in real time throughout the experiment. At the start, the super-capacitor is fully discharged. In the first phase, only the OSC and the super-capacitor are connected. Light of either $100 \mathrm{~mW} \cdot \mathrm{cm}^{-2}$ (1-sun) or $310 \mu \mathrm{W} . \mathrm{cm}^{-2}$ (typical indoor) is shone on the solar cell. When the system starts to saturate, the super-capacitor is disconnected from the OSC, briefly isolated and connected to the resistive load for discharge. Identical experiments performed with $1 \Omega, 10 \Omega$ were compared with the $120 \Omega$ and did not yield any significant difference in the results (about $2 \%$ Table S3). The total number of charges extracted are calculated by integrating the discharge current over time. The effective capacitance of the 
super-capacitor is calculated as the ratio of extracted charges and the maximum voltage $V_{\max }$ of the isolated super-capacitor after charge. The stored energy is then derived as $E=\frac{1}{2} C \times$ $V_{\max }{ }^{2}$. The maximum power extracted is calculated as the product of current and voltage at the very beginning of the discharge. Finally, the ECSE is calculated as the ratio of stored energy and light energy received during the charge phase. Figure 6 shows the voltage and current flowing through the super-capacitor during a typical charge-discharge experiment under 1-sun (Figure 6 a) and simulated indoor light (Figure 6 b) using the solar cell with thick PEIE. In both cases, the voltage starts at $0 \mathrm{~V}$ and the current is the short-circuit current of the solar cell. As the voltage rises, the output current of the solar cell corresponds to its $\mathrm{J}-\mathrm{V}$ characteristic. In the 1-sun case, the voltage quickly saturates, reaching $870 \mathrm{mV}$ in 28 seconds, $50 \mathrm{mV}$ below the $\mathrm{V}_{\mathrm{oc}}$ of the solar cell. Simultaneously, the current decreases from $4.5 \mathrm{~mA}$ (the short-circuit current) to below $1 \mathrm{~mA}$. As a result, the charge is stopped after $35 \mathrm{~s}$. A visible voltage drop occurs when stopping the charge (from $870 \mathrm{mV}$ to $740 \mathrm{mV}$ ), indicating an equivalent series resistance of $130 \Omega$, three times higher than expected from the earlier characterization of the super-capacitor. The current peaks at the start of the discharge phase, reaching $5.7 \mathrm{~mA}$, and very quickly decreases, as does the voltage. It should be noted that more than $70 \%$ of the total number of charges are extracted during the first second of discharge. Under simulated indoor light, the system behaves quite differently. Over a charge period of 3000 seconds, the voltage rises steadily while the current is mostly stable, between 18 and $15 \mu \mathrm{A}$. When charging stops, the final voltage is $530 \mathrm{mV}$, well below the $\mathrm{V}_{\text {oc }}$ of 740 $\mathrm{mV}$ and no voltage drop is visible. In this case, the limiting factor is the leakage current of the super-capacitor, estimated to reach approximately $15 \mu \mathrm{A}$ at $500 \mathrm{mV}$ of bias voltage. During discharge, $50 \%$ of the total stored charges are extracted within 1 second and more than $90 \%$ after 2 seconds. The trends identified here are representative of all the other charge/discharge experiments performed in this work. These observations suggest several guidelines for 
improving the system's operation: under strong light, it is preferable to have as high a $\mathrm{V}_{\mathrm{oc}}$ as possible (possibly with cells connected in series or using a tandem)[28] in order to maximize the amount of energy stored in the super-capacitor. At lower light intensity however, the priority should be to increase the current of the solar cell (by improving the EQE or the absorption, or using tandem cells connected in parallels for example). Minimizing the leakage current and series resistance of the super-capacitor is also paramount to maximize energy harvesting.

To investigate the influence of the solar cell efficiency on the ECSE, such chargedischarge experiments in the two lighting conditions are performed three times each using either a medium PEIE solar cell (optimal under 1-sun) or thick PEIE one (optimal for indoor light). Table 2 a-b summarizes the performances of the two systems. The charging time under 1-sun is 35 seconds, while it is kept at 900 seconds in indoor conditions to ensure that the super-capacitor's leakage current does not impact the results. Under 1-sun, the systems with the two cells perform nearly identically. The total energy extracted is $26 \mathrm{~mJ}$ for both of them at a maximum power of $4 \mathrm{~mW}$. These energy and power levels are exactly in the range needed to power the active mode of the WSN (1-10 $\mathrm{mJ}$ and 1-10 $\mathrm{mW})$. The ECSE of the two systems reach $1.56 \%$, the highest to date for photo-rechargeable systems using OSC. When the two systems are compared under indoor light for $900 \mathrm{~s}$, the ECSE amounts to $1.07 \%$ for the system with the medium PEIE and to $1.21 \%$ with the thick PEIE. Using the solar cell optimized for indoor light thus yields a $15 \%$ improvement in the ECSE of the photorechargeable system and this improvement is passed on to the other metrics, as the maximum power and extracted energy also boast a $15 \%$ improvement. However, the extracted energy and power are an order of magnitude lower than under 1-sun. This can partially be explained because after $900 \mathrm{~s}$, the voltage across the super-capacitor is still very low $(<200 \mathrm{mV})$ and the energy stored into a super-capacitor varies with the square of the voltage. Moreover, work by 
$\mathrm{Xu}$ and co-workers [32] suggests that the ECSE of a given system (and thus the stored energy) depends highly on the charging time.

To verify if charging for a long time under indoor light would allow the storage of similar levels of energy and power as the 1-sun scenario, the charging time is increased to 3090 seconds (Table $2 \mathrm{c}$ ). The maximum voltage attained is $530 \mathrm{mV}$, the extracted energy is $13.3 \mathrm{~mJ}$ and the maximum power $1.26 \mathrm{~mW}$. These levels are of the same order of magnitude as under 1-sun and are therefore suitable for low-power applications. It is noteworthy that, between those two experiments, the light power was decreased 300 -fold and the charging time only increased 88-fold, yet the energy stored in the indoor scenario is half that of the 1-sun scenario. If the system had behaved linearly, only one-third would have been expected. This is promising for indoor-applications: photo-rechargeable systems behave in a non-linear manner that narrows the gap between high and low light intensity. This will be critical to reduce the charging time needed under low-light. As a result, the ECSE reaches $2.92 \%$. Interestingly, the coulombic efficiency (calculated by comparing the quantity of charges that flowed into and out of the super-capacitor during the charge and discharge steps) in these experiments equals $95 \%$, suggesting that the leakage current of the super-capacitor is much lower than anticipated. Overall, these results demonstrate that OSC coupled with super-capacitors are well-suited to cover the energy needs of low-consumption devices, even when operating in low-light environments such as indoors. This opens up new, industrially-significant, perspectives of applications for organic solar cells, where the constraints are considerably different from the usual outdoor photovoltaic installations.

\section{Conclusion}

In conclusion, organic solar cells for indoor operation need to be specifically optimized for these conditions. Particularly, achieving a low dark current is essential to 
maintaining a high PCE under low light intensities. Optimizing the thickness of the PEIE layer is an efficient way of controlling the dark current and cells with PCE of $7.6 \%$ under simulated indoor light were demonstrated. The ratio of dark current over short-circuit current was identified as a reliable indicator of the minimal light power below which a cell's efficiency decreases sharply. Fully-printed super-capacitors were developed, showing a maximum discharge capacitance of $130 \mathrm{mF} . \mathrm{cm}^{-2}$, and provided a maximum power of 9.8 $\mathrm{mW} . \mathrm{cm}^{-2}$, and maximum energy of $31 \mu \mathrm{W}-\mathrm{hr} . \mathrm{cm}^{-2}$. Those super-capacitors were integrated with OSC to form photo-rechargeable systems. Under 1-sun light, such systems had $1.56 \%$ of ECSE and generated $26 \mathrm{~mJ}$ of energy and up to $4 \mathrm{~mW}$ of power. Under simulated indoor light, photo-rechargeable systems using OSC optimized for indoor operation yielded $15 \%$ more energy per cycle than those using OSC optimized for 1-sun. The indoor-optimal photorechargeable system charged under indoor light for 3090 seconds provides energy and power levels similar to the 1-sun scenario, and reaches $2.92 \%$ of ECSE. Overall, these results suggest that organic solar cells have a good potential to power autonomous applications in various light environments.

\section{Acknowledgements}

The authors would like to thank Dr Igal Deckman and Aminy Ostfeld, as well as Pr. Raphael

Clerc for helpful discussion. This work was partially supported by the National Science

Foundation (NSF) grant No ECCS-1202189, the NSF Graduate Fellowship Program Grant No

DGE-1106400, and by FlexTech RFP 13-161.

\section{References}


[1] Z. He, B. Xiao, F. Liu, H. Wu, Y. Yang, S. Xiao, C. Wang, T.P. Russell, Y. Cao, Nat Photon 9 (2015) 174-179.

[2] C.-C. Chen, W.-H. Chang, K. Yoshimura, K. Ohya, J. You, J. Gao, Z. Hong, Y. Yang, Adv Mater 26 (2014) 5670-5677.

[3] C.H. Peters, I.T. Sachs-Quintana, J.P. Kastrop, S. Beaupré, M. Leclerc, M.D. McGehee, Adv Energy Mater 1 (2011) 491-494.

[4] S.A. Gevorgyan, M.V. Madsen, B. Roth, M. Corazza, M. Hösel, R.R. Sondergaard, M. Jorgensen, F.C. Krebs, Adv. Energy Mater. (2015) n/a-n/a.

[5] C.J.M. Emmott, A. Urbina, J. Nelson, Dedic. Glob. Org. Photovolt. GOPV Conf. Hangzhou China 97 (2012) 14-21.

[6] N. Espinosa, M. Hosel, D. Angmo, F.C. Krebs, Energy Env. Sci 5 (2012) 5117-5132.

[7] T.R. Andersen, H.F. Dam, M. Hosel, M. Helgesen, J.E. Carle, T.T. Larsen-Olsen, S.A. Gevorgyan, J.W. Andreasen, J. Adams, N. Li, F. Machui, G.D. Spyropoulos, T. Ameri, N. Lemaitre, M. Legros, A. Scheel, D. Gaiser, K. Kreul, S. Berny, O.R. Lozman, S. Nordman, M. Valimaki, M. Vilkman, R.R. Sondergaard, M. Jorgensen, C.J. Brabec, F.C. Krebs, Energy Env. Sci (2014) -.

[8] F. Guo, X. Zhu, K. Forberich, J. Krantz, T. Stubhan, M. Salinas, M. Halik, S. Spallek, B. Butz, E. Spiecker, T. Ameri, N. Li, P. Kubis, D.M. Guldi, G.J. Matt, C.J. Brabec, Adv Energy Mater 3 (2013) 1062-1067.

[9] M. Hösel, R.R. Søndergaard, M. Jørgensen, F.C. Krebs, Adv Energy Mater 4 (2014) n/a-n/a.

[10] D. Angmo, F.C. Krebs, Energy Technol. 3 (2015) 774-783.

[11] F. Karray, M.W. Jmal, M. Abid, M.S. BenSaleh, A.M. Obeid, in:, Reconfigurable Commun.-Centric Syst.--Chip ReCoSoC 2014 9th Int. Symp., 2014, pp. 1-8.

[12] M. Healy, T. Newe, E. Lewis, in:, Sens. 2008 IEEE, 2008, pp. 621-624.

[13] J.A. Khan, H.K. Qureshi, A. Iqbal, Comput. Electr. Eng. 41 (2015) 159-176.

[14] L. Roselli, N. Borges Carvalho, F. Alimenti, P. Mezzanotte, G. Orecchini, M. Virili, C. Mariotti, R. Goncalves, P. Pinho, Proc. IEEE 102 (2014) 1723-1746.

[15] N.H. Reich, M. Veefkind, W.G.J.H.M. van Sark, E.A. Alsema, W.C. Turkenburg, S. Silvester, Sol. Energy 83 (2009) 202-210.

[16] J. Quill, G. Fedor, P. Brennan, P. Everett, Quantifying the Indoor Light Environment, QLab Corporation, 2007.

[17] B. Minnaert, P. Veelaert, Energies 7 (2014) 1500-1516.

[18] M. Freunek, M. Freunek, L.M. Reindl, Photovolt. IEEE J. Of 3 (2013) 59-64.

[19] C. Lungenschmied, G. Dennler, H. Neugebauer, S.N. Sariciftci, M. Glatthaar, T. Meyer, A. Meyer, Sel. Pap. Eur. Conf. Hybrid Org. Sol. Cells - ECHOS 06 Eur. Conf. Hybrid Org. Sol. Cells 91 (2007) 379-384.

[20] K. Ruhle, M.K. Juhl, M.D. Abbott, M. Kasemann, Photovolt. IEEE J. Of 5 (2015) 926931.

[21] Y. Xu, I. Hennig, D. Freyberg, A. James Strudwick, M. Georg Schwab, T. Weitz, K. Chih-Pei Cha, J. Power Sources 248 (2014) 483-488.

[22] J. Yeo, G. Kim, S. Hong, M.S. Kim, D. Kim, J. Lee, H.B. Lee, J. Kwon, Y.D. Suh, H.W. Kang, H.J. Sung, J.-H. Choi, W.-H. Hong, J.M. Ko, S.-H. Lee, S.-H. Choa, S.H. Ko, J. Power Sources 246 (2014) $562-568$.

[23] D. Schmidt, M.D. Hager, U.S. Schubert, Adv Energy Mater (2015) n/a-n/a.

[24] D. Brunelli, C. Moser, L. Thiele, L. Benini, Circuits Syst. Regul. Pap. IEEE Trans. On 56 (2009) 2519-2528.

[25] P. Du, X. Hu, C. Yi, H.C. Liu, P. Liu, H.-L. Zhang, X. Gong, Adv Funct Mater 25 (2015) 2420-2427.

[26] T. Chen, L. Qiu, Z. Yang, Z. Cai, J. Ren, H. Li, H. Lin, X. Sun, H. Peng, Angew Chem Int Ed 51 (2012) 11977-11980. 
[27] C.-T. Chien, P. Hiralal, D.-Y. Wang, I.-S. Huang, C.-C. Chen, C.-W. Chen, G.A.J. Amaratunga, Small 11 (2015) 2929-2937.

[28] G. Wee, T. Salim, Y.M. Lam, S.G. Mhaisalkar, M. Srinivasan, Energy Env. Sci 4 (2011) $413-416$.

[29] X. Wang, X. Lu, B. Liu, D. Chen, Y. Tong, G. Shen, Adv Mater 26 (2014) 4763-4782.

[30] A.P. Cohn, W.R. Erwin, K. Share, L. Oakes, A.S. Westover, R.E. Carter, R. Bardhan, C.L. Pint, Nano Lett. 15 (2015) 2727-2731.

[31] Z. Yang, L. Li, Y. Luo, R. He, L. Qiu, H. Lin, H. Peng, J Mater Chem A 1 (2013) 954958.

[32] J. Xu, H. Wu, L. Lu, S.-F. Leung, D. Chen, X. Chen, Z. Fan, G. Shen, D. Li, Adv Funct Mater 24 (2014) 1840-1846.

[33] M. Skunik-Nuckowska, K. Grzejszczyk, P.J. Kulesza, L. Yang, N. Vlachopoulos, L. Häggman, E. Johansson, A. Hagfeldt, J. Power Sources 234 (2013) 91 - 99.

[34] T. Chen, Z. Yang, H. Peng, ChemPhysChem 14 (2013) 1777-1782.

[35] X. Zhang, X. Huang, C. Li, H. Jiang, Adv Mater 25 (2013) 4093-4096.

[36] S.H. Park, A. Roy, S. Beaupre, S. Cho, N. Coates, J.S. Moon, D. and Moses, M. Leclerc, K. Lee, A.J. Heeger, Nat. Photonics 3 (2009) 297-302.

[37] C.M. Proctor, T.-Q. Nguyen, Appl. Phys. Lett. 106 (2015) 083301.

[38] R. Steim, T. Ameri, P. Schilinsky, C. Waldauf, G. Dennler, M. Scharber, C.J. Brabec, Sol. Energy Mater. Sol. Cells 95 (2011) 3256 - 3261.

[39] Y. Zhou, T.M. Khan, J.W. Shim, A. Dindar, C. Fuentes-Hernandez, B. Kippelen, J Mater Chem A 2 (2014) 3492-3497.

[40] Y. Zhou, C. Fuentes-Hernandez, J. Shim, J. Meyer, A.J. Giordano, H. Li, P. Winget, T. Papadopoulos, H. Cheun, J. Kim, M. Fenoll, A. Dindar, W. Haske, E. Najafabadi, T.M. Khan, H. Sojoudi, S. Barlow, S. Graham, J.-L. Brédas, S.R. Marder, A. Kahn, B. Kippelen, Science 336 (2012) 327-332.

[41] P. Li, G. Wang, L. Cai, B. Ding, D. Zhou, Y. Hu, Y. Zhang, J. Xiang, K. Wan, L. Chen, K. Alameh, Q. Song, Phys Chem Chem Phys 16 (2014) 23792-23799.

[42] A. Pierre, I. Deckman, P.B. Lechene, A.C. Arias, Adv Mater 27 (2015) 6411-6417.

[43] G.A.H. Wetzelaer, M. Kuik, M. Lenes, P.W.M. Blom, Appl. Phys. Lett. 99 (2011) 153506.

[44] B. Bouthinon, R. Clerc, J. Vaillant, J.-M. Verilhac, J. Faure-Vincent, D. Djurado, I. Ionica, G. Man, A. Gras, G. Pananakakis, R. Gwoziecki, A. Kahn, Adv. Funct. Mater. 25 (2015) 1090-1101.

[45] K. Ellmer, Nat Photon 6 (2012) 809-817.

[46] A.E. Ostfeld, A. Catheline, K. Ligsay, K.-C. Kim, Z. Chen, A. Facchetti, S. Fogden, A.C. Arias, Appl. Phys. Lett. 105 (2014) 253301.

[47] M. Cowell, R. Winslow, Q. Zhang, J. Ju, J. Evans, P. Wright, J. Phys. Conf. Ser. 557 (2014) 012061.

[48] J.S. Newman, C.W. Tobias, J. Electrochem. Soc. 109 (1962) 1183-1191.

[49] L. Zubieta, R. Bonert, Ind. Appl. IEEE Trans. On 36 (2000) 199-205. 


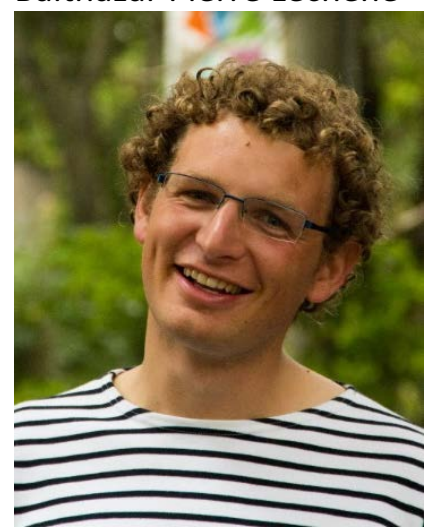

Balthazar P. Lechene is a post-doc in the department of Electrical Engineering and Computer Sciences at the University of California, Berkeley. He received his Ph.D at the French National Institute for Solar Energy (INES) in 2013 for his work on tandem organic solar cells. His research focuses on printed electronics for energy harvesting and biomedical applications.

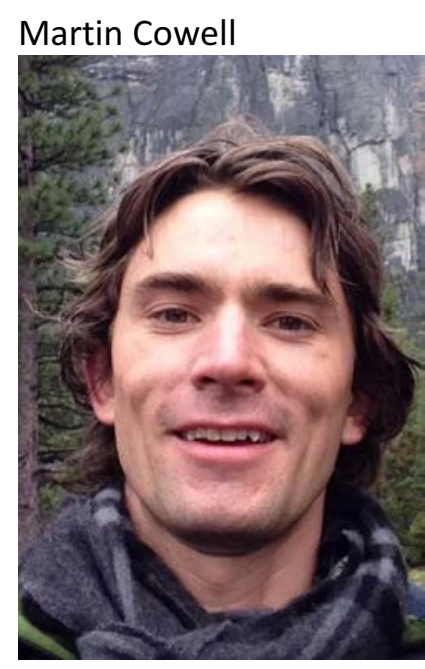

Martin A. Cowell is a Ph.D. student researcher in the Department of Mechanical Engineering at the University of California, Berkeley. His role as project lead for high-power energy storage in the Advanced Manufacturing for Energy laboratory involves model-based supercapacitor design and device manufacture. Martin received his B.Sc. degree from the Colorado School of Mines in 2013 and has since worked in industry and academia, supporting projects for a data-driven future. 


\section{Adrien Pierre}

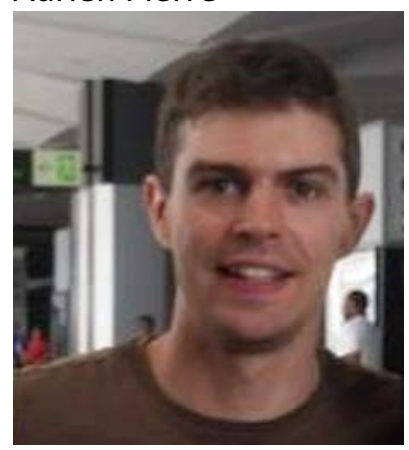

Adrien Pierre is pursuing his Ph.D. in the department of Electrical Engineering and Computer Sciences at the University of California, Berkeley. Adrien received his B.Eng. from McGill University, where he researched compound semiconductor nanoparticles for photocatalytic water splitting for hydrogen generation. His current academic interests include printed transistors and high performance photodetectors on flexible substrates as enabling technologies for inexpensive high-sensitivity image sensors.

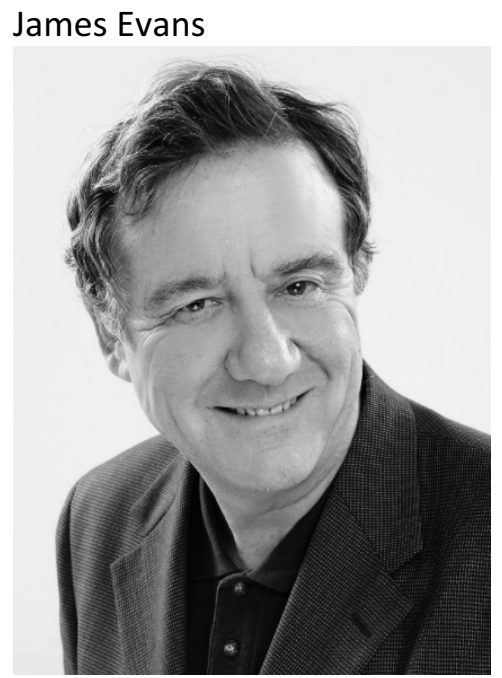

James W. Evans is the Plato Malozemoff Professor Emeritus in the Department of Materials Science and Engineering, University of California, Berkeley. His research has been on the processes used for the production of materials, particularly the physical and chemical phenomena entailed in such processes. More recently he has carried out research on energy harvesting and storage (in batteries and supercapacitors) in collaboration with colleagues in Mechanical Engineering. His work has resulted in over 390 publications, including four books. Thirty-five students have gained the Ph.D. under his supervision; six are on the faculty at major universities in the US and abroad. 
Paul Wright

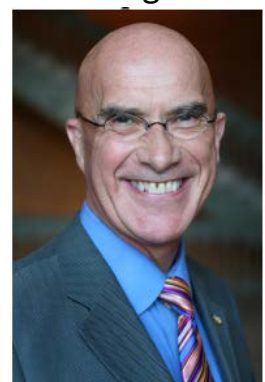

Paul Wright is the A. Martin Berlin Professor of Mechanical Engineering and Director of the Berkeley Energy and Climate Institute. His research takes place in the Advanced Manufacturing for Energy (AME) laboratory. Funds from industry, foundations, the federal government, and the California Energy Commission (CEC), support an integrated research program on the resilience \& analytics of energy systems. Individual PhD projects cover a broad spectrum: Energy harvesting; 3D printing of storage systems for the Internet of Things; MEMS-sensors for electrical-grids and gas distribution; Demand Response, and Condition Based Monitoring (CbM) of energy systems.

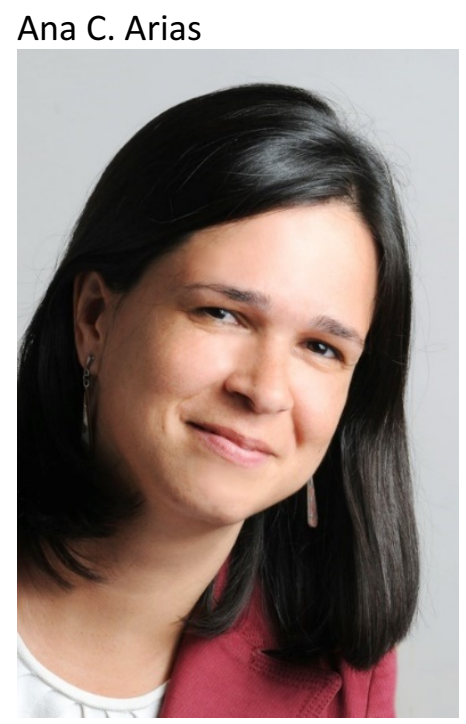

Ana Claudia Arias is an Associate Professor at the Electrical Engineering and Computer Sciences Department and a faculty director of the Berkeley Wireless Research Center (BWRC) and the Swarm Lab at the University of California in Berkeley. She received her Ph.D. on semiconducting polymer blends for photovoltaic devices from the Physics Department at the University of Cambridge, UK. Prior to that, she received her master and bachelor degrees in Physics from the Federal University of Paraná in Curitiba, Brazil. Her research focuses on devices based on solution processed materials and applications development for flexible sensors and electronic systems. 
Below are the captions for the figures:

Figure 1. a) Architecture of the solar cells used in this work. B) Normalized power spectra of the different light sources studied: 1-sun AM 1.5G (line), incandescent light bulb $2800 \mathrm{~K}$ (red squares), CFL $6500 \mathrm{~K}$ (blue triangles), LED $3000 \mathrm{~K}$ (green crosses), and the normalized absorption spectrum of the solar cell (pink dots).

Figure 2. Dependence as a function of light intensity of a) the open-circuit voltage, b) shortcircuit current, c) fill factor and d) PCE of solar cells with three different PEIE thickness (Thin, Medium and Thick). The dotted lines represent linear trends with the indicated slope.

Figure 3. J-V characteristics of three cells with varying PEIE thickness a) under 1-sun illumination, b) under simulated indoor light and c) in the dark.

Figure 4. Effects of adding increasing values of resistance in series with an organic solar cell under 1-sun and simulated indoor light. a) Dependence of the PCE as a function of the resistance value. Because of the log-scale, the $1 \Omega$ data points correspond to no added resistance. The black squares are data for 1-sun while the red dots are for indoor light. B) J-V characteristics of the solar cell for different added resistance values under 1-sun and c) under simulated indoor lighting.

Figure 5. a) Structure of the super-capacitor along with its b) Ragone plot, c) capacitance and coulombic efficiency as a function of the charge/discharge current and d) dependence of the leakage current as a function of bias voltage.

Figure 6. Typical variations of the absolute current flowing through the super-capacitor (black squares) and voltage across it (red dots) during the charge discharge experiment of a photorechargeable system comprising a solar cell optimized for indoor operation and a supercapacitor. a) Under 1-sun light, where the charge stops after 35 seconds and b) under simulated indoor light, where the charge stops after 3090 seconds. 
Figure 1

a)

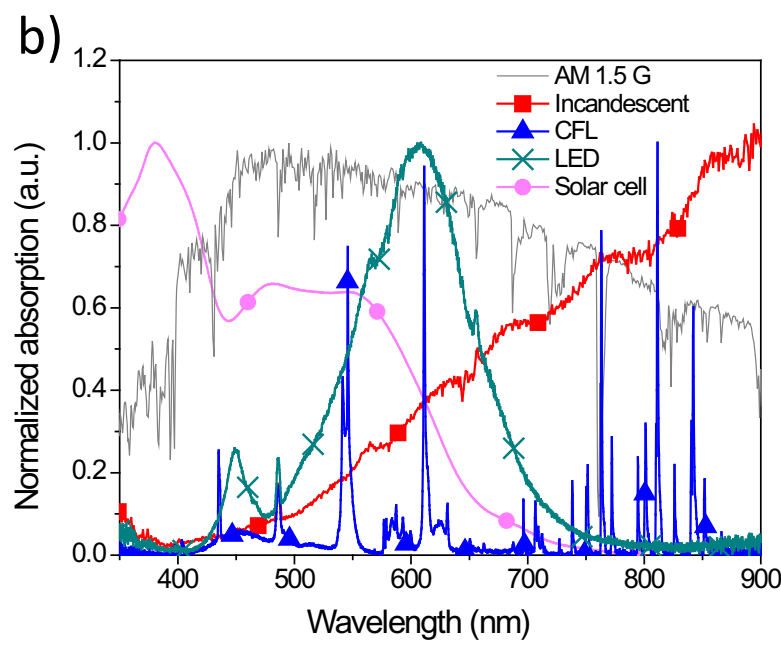




\section{Figure 1}

a)

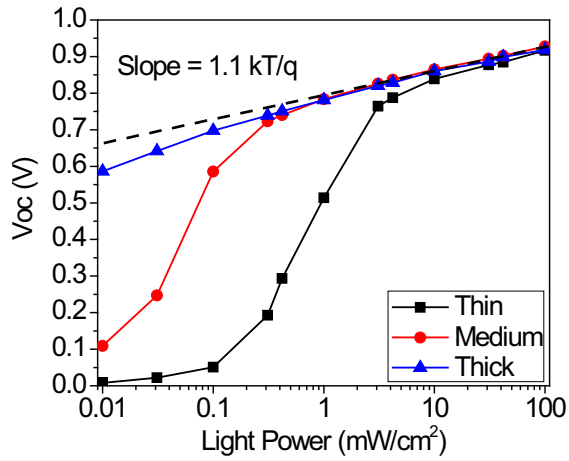

c)

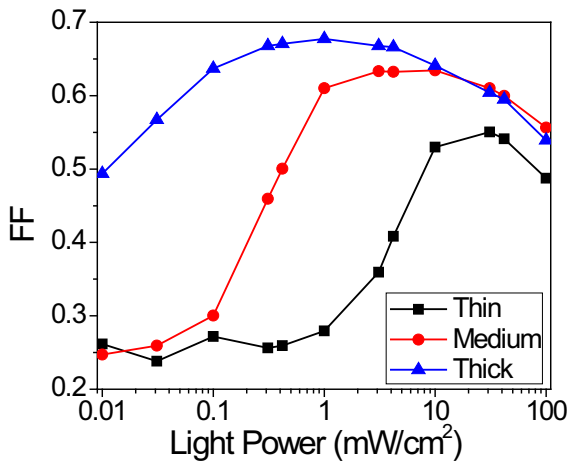

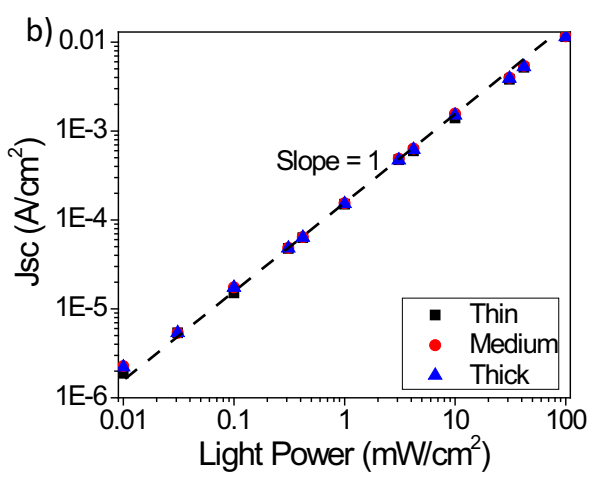

d)

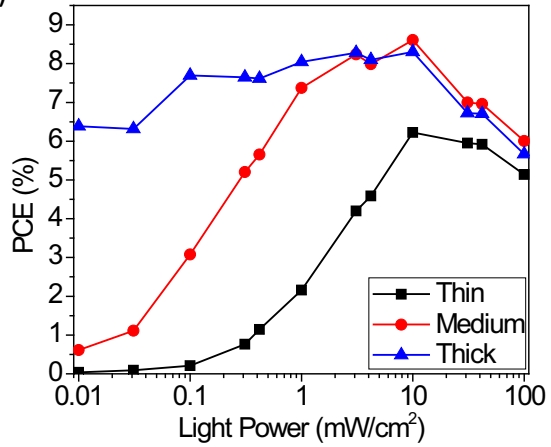


a) Figure 3

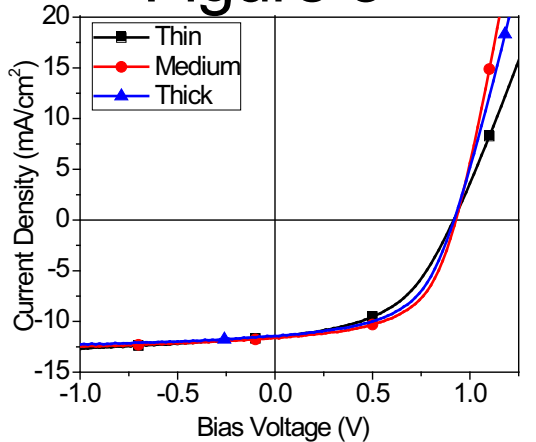

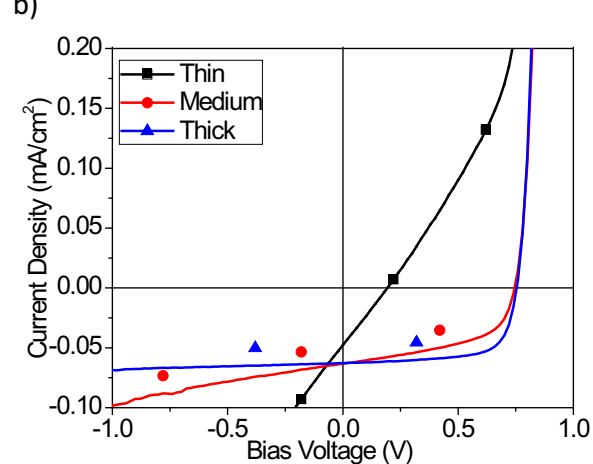

c)

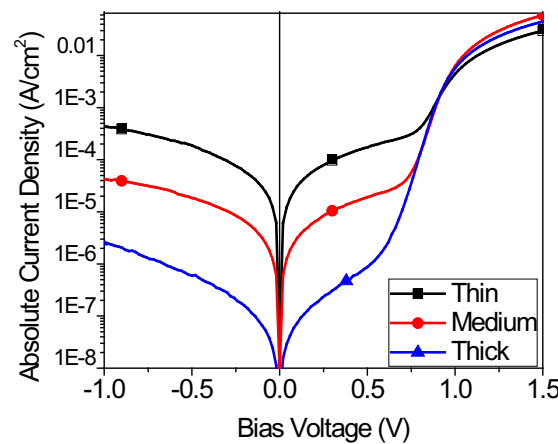


Figure 5

a)

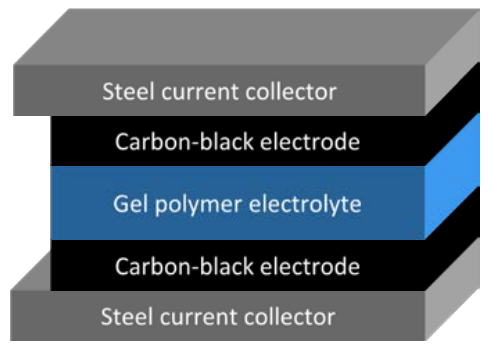

c)

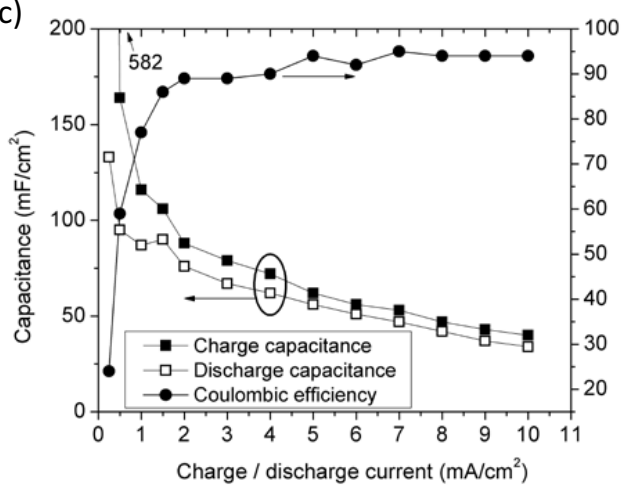

b)

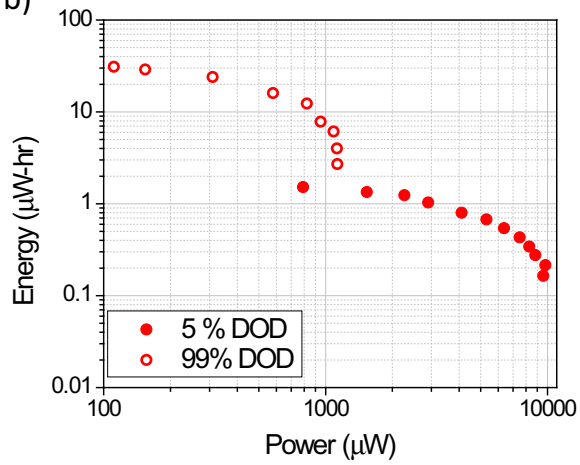

d)

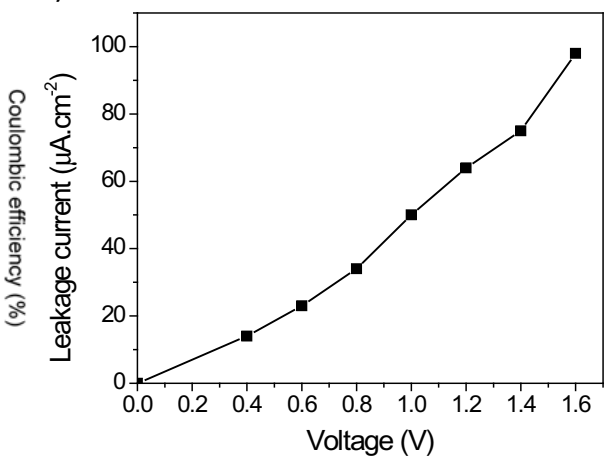


Figure 6
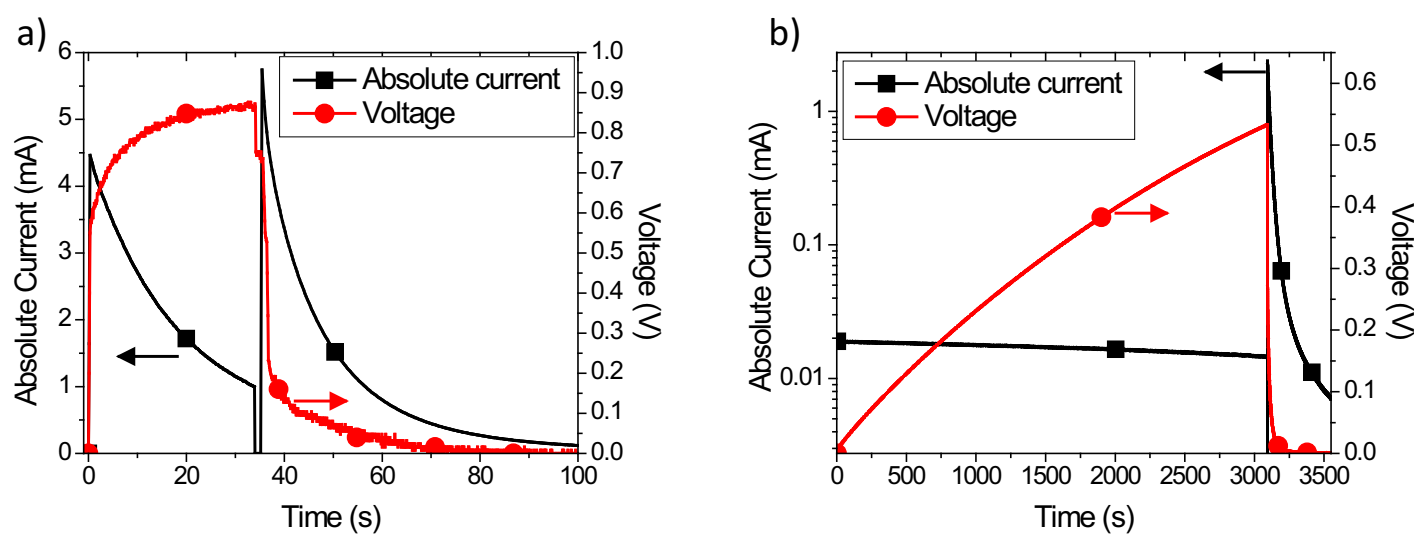
Graphical Abstract

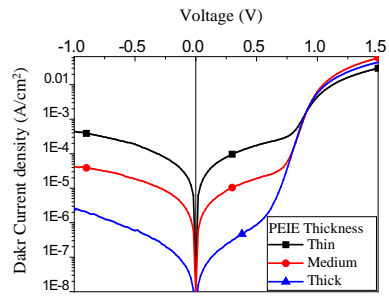

Light Power (mW.cm-2)

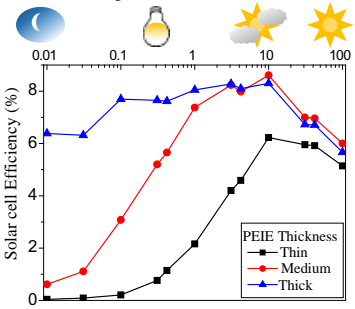


Table 1. Light power corresponding to 300 lux illuminance emitted by three representative types of light bulbs (LED $3000 \mathrm{~K}$, CFL $6500 \mathrm{~K}$ and incandescent bulbs $2800 \mathrm{~K}$,), and light power of a standard AM 1.5G sun-light spectrum dimmed to 340 lux. Power generated by our organic solar cell exposed to these different light sources and the corresponding PCE, opencircuit voltage, short-circuit current and fill factor.

\begin{tabular}{|c|c|c|c|c|c|c|}
\hline $\begin{array}{c}\text { Light source } \\
\text { and illuminance } \\
\text { [lux] }\end{array}$ & $\begin{array}{l}\text { Corresponding } \\
\text { light power } \\
{\left[\mathrm{mW} / \mathrm{cm}^{2}\right]}\end{array}$ & $\begin{array}{l}\text { Power generated } \\
\text { by solar cell } \\
{\left[\mu \mathrm{W} / \mathrm{cm}^{2}\right]}\end{array}$ & $\begin{array}{l}\text { PCE } \\
{[\%]}\end{array}$ & $\begin{array}{l}\text { Voc } \\
{[\mathrm{mV}]}\end{array}$ & $\begin{array}{c}J \mathrm{sc} \\
{[\mu \mathrm{A} / \mathrm{cm}]}\end{array}$ & $\begin{array}{l}\mathbf{F F} \\
{[\%]}\end{array}$ \\
\hline Sun (340) & 0.31 & 15.2 & 4.9 & 704 & 4.7 & 45 \\
\hline LED (300) & 0.104 & 9.0 & 8.7 & 702 & 28.0 & 46 \\
\hline CFL (300) & 0.18 & 20.7 & 11.5 & 738 & 53.5 & 53 \\
\hline Incandescent bulb (300) & 0.633 & 3.8 & 0.6 & 645 & 16.5 & 34 \\
\hline
\end{tabular}

Table 2. Comparisons of the photo-rechargeable systems using either a solar cell optimized for 1-sun operation (medium PEIE) or for indoor operation (thick PEIE), under either 1-sun of light $\left(100 \mathrm{~mW} . \mathrm{cm}^{-2}\right)$ or simulated indoor light $\left(0.31 \mathrm{~mW} . \mathrm{cm}^{-2}\right)$. Indication of the charging time, the maximum voltage across the super-capacitor at the start of discharge, the total quantity of charges, total energy and maximum power extracted from the super-capacitor during discharge. Energy conversion and storage efficiency of the whole photo-rechargeable system calculated from the previous values.

\begin{tabular}{|c|c|c|c|c|c|c|c|c|}
\hline & $\begin{array}{l}\text { Solar } \\
\text { Cell }\end{array}$ & $\begin{array}{c}\text { Light } \\
\text { Power } \\
{\left[\mathrm{mW} . \mathrm{cm}^{-2}\right]}\end{array}$ & $\begin{array}{c}\text { Charging } \\
\text { time } \\
{[s]}\end{array}$ & $\begin{array}{c}\text { Maximum } \\
\text { Voltage } \\
{[\mathrm{mV}]}\end{array}$ & $\begin{array}{l}\text { Extracted } \\
\text { charges } \\
{[\mathrm{mC}]}\end{array}$ & $\begin{array}{c}\text { Extracted } \\
\text { energy } \\
{[\mathrm{mJ}]}\end{array}$ & $\begin{array}{c}\text { Maximum } \\
\text { Power } \\
{[\mathrm{mW}]}\end{array}$ & $\begin{array}{c}\text { ECSE } \\
{[\%]}\end{array}$ \\
\hline \multirow[t]{2}{*}{ a) } & $\begin{array}{l}\text { Medium } \\
\text { PEIE }\end{array}$ & 100 & $35.1+/-0.1$ & $730+/-5$ & $71.2+/-0.2$ & $26.0+/-0.2$ & $4.06+/-0.07$ & $1.56+/-0.01$ \\
\hline & $\begin{array}{l}\text { Thick } \\
\text { PEIE }\end{array}$ & 100 & $35.1+/-0.1$ & $730+/-5$ & $71.7+/-0.2$ & $26.2+/-0.2$ & $4.16+/-0.04$ & $1.57+/-0.01$ \\
\hline \multirow[t]{2}{*}{ b) } & $\begin{array}{l}\text { Medium } \\
\text { PEIE }\end{array}$ & 0.31 & $900+/-0.2$ & $160+/-5$ & $18.2+/-0.1$ & $\begin{array}{c}1.42+/- \\
0.06\end{array}$ & $0.19+/-0.01$ & $1.07+/-0.04$ \\
\hline & $\begin{array}{l}\text { Thick } \\
\text { PEIE }\end{array}$ & 0.31 & $900+/-0.1$ & $170+/-5$ & $19.0+/-0.1$ & $\begin{array}{c}1.61+/- \\
0.06\end{array}$ & $0.22+/-0.01$ & $1.21+/-0.04$ \\
\hline c) & $\begin{array}{l}\text { Thick } \\
\text { PEIE }\end{array}$ & 0.31 & $3090+/-0.1$ & $530+/-5$ & $50.0+/-0.3$ & $13.3+/-0.2$ & $1.26+/-0.02$ & $2.92+/-0.02$ \\
\hline
\end{tabular}

